\title{
SAĞLIK HİZMETLERİ PIYYASASI VE KOMPÜTASYONEL MODELLEME
}

\author{
Demet TOPAL $\mathrm{KOÇ}^{1 *}$ \\ ${ }^{1}$ Kırklareli Üniversitesi, Sağlık Yüksekokulu, Sağlık Yönetimi Bölümü, Kırklareli, Yıldız Teknik Üniversitesi, İktisat \\ Bölümü, İstanbul/TÜRKIYYE
}

\section{ÖZET}

Sağlık hizmetleri ve sağlık hizmetleri piyasası kompleks adaptif sistemdir. Dolayısıyla, klasik Newton matematiğini kullanan yöntemlerden elde edilen tek bir çözüm ile sağlık hizmetleri piyasasının değerlendirilmesi, analiz edilmesi ve çözüm önerilerinin geliştirilmesi yeterli değildir. Klasik matematiksel araçlar yerine, kompleks sistemi analiz eden araçların ve yöntemlerin kullanılması gerekir. Böylece sistem gerçeğe daha yakın modellenirken, genellikle tek bir çözüm yerine çözüm kümesi sunan yöntemler ile sorunlara daha etkin çözümler bulunabilmektedir. Bu bağlamda, bu derleme çalışmasında konu ile ilgili bir kılavuz olması açısından sağlık hizmetleri ve sağlık hizmetleri piyasasını değerlendirmede kompleks sistem analiz araçlarını kullanan çalışmalar araştırılmıştır. Çalışmada, öncelikle kompleks adaptif sistemleri analiz ederken en sık kullanılan ajan bazlı modelleme, sistem dinamiği ve ayrık olay simülasyonu gibi yöntemler kısaca açıklanmış ve sonrasında bu yöntemleri kullanılan literatüre yer verilmiştir.

Anahtar Kelimeler: Ajan bazlı modelleme, Sistem dinamiği modellemesi, Sağlık hizmetleri piyasası, Sağlık ekonomisi, Kompütasyonel iktisat

\section{HEALTHCARE MARKET AND COMPUTATIONAL MODELLING}

\begin{abstract}
Healthcare market is one of complex adaptive systems. Therefore, the methods using Newtonian mathematics usually give a solution that is not sufficient for analysis, examining and finding solutions for this complex system. Instead of classic mathematical tools, healthcare market evaluation studies need complex adaptive system tools. Using these methods and toolkits, the healthcare market can be modelled more closely to real life. That's why, the system is modelled more closely to real life, instead of to find just one solution, can be get more effective solutions with the methods can give a solution set. The aim of this study is to guide researchers interested in computational methods such as agent-based model, system dynamics model and discrete event simulation in healthcare market. So in this study, firstly, these complex system analysis methods are examined and then the literature that use these complex methods are presented.
\end{abstract}

Keywords: Agent based modelling, System dynamics modelling, Healthcare market, Health economics, Computational economics

*Sorumlu Yazar: demettopalkoc@klu.edu.tr 


\section{Derleme}

DOI: $10.34186 /$ klujes.786837
Koç/Kırklareli University Journal of Engineering and Science 6-2(2020) 238-253

Geliş Tarihi:28.08.2020
Kabul Tarihi:31.12.2020

\section{GİRIŞ}

Çok katmanlı ve birbirine bağımlı, kendi kendini organize eden ve evirilebilen, nonlineer ve yol bağımlılığı olan sistemler kompleks adaptif sistemlerdir [1]. Sağlık sistemleri, heterojen birimler ve bunların oluşturduğu süreçler açısından kompleks adaptif bir sistemdir [2]. Bu durum, sağlik sistemi davranışlarını tahmin etmede ve sistemin etkin yönetimi konusunda, geleneksel yöntemlerin yetersiz kalmasına neden olmaktadır. Sağlık hizmetleri piyasasını analiz etmede kullanılan geleneksel yaklaşım yöntemleri çeşitli varsayımlar ve belirli bir durumu ele alır. Ancak sistemi genel olarak anlamak ve gerçekçi çözümler sunabilmek için kompleks sistem analiz araçlarına ihtiyaç duyulmaktadır. Sağlık sistemi yerel, bölgesel, ulusal ve uluslararası olmak üzere aile hekimliklerinden ü̧̈üncü derece kapsamlı hastanelere kadar çeşitli büyüklükteki sağlık kuruluşları ile çok katmanlı yapıdadır. Dolayısıyla performansın değerlendirilmesi, etkin politikaların sunulması ve optimizasyonun sağlanmasında sadece maliyet etkililik, maliyet yarar gibi matematiksel çözümler yerine daha az varsayım kullanarak, sistemi ayrıntılı şekilde modelleyebilecek kompütasyonel yöntemlere ihtiyaç duyulmaktadır.

Sağlık hizmetleri pek çok açıdan değerlendirilebilir. Bu çalışmada özellikle sağlık hizmetleri piyasası ele alınmaktadır. Çalışmada öncelikle sağlık hizmetleri piyasası ve kompütasyonel modelleme kısaca açıklanmaktadır. Sonrasında söz konusu yöntemlerden sistem dinamiği ve ajan bazlı modelleme yöntemlerine değinilerek, bu yöntemlerle yapılan çalışmalara yer verilmektedir. Son olarak, yapılan çalışmalar genel olarak değerlendirilmektedir.

\section{Sağlık Hizmetleri Piyasası}

Ekonomi için önemli bir kavram olan sağlı̆̆ın, kazanılması ve korunması amacıyla gerçekleştirilen tüm faaliyetler sağlık hizmetleri olarak tanımlanmaktadır. Kaybedilen sağlık durumunun tekrar kazanılması ve korunabilmesi için, sunulan hizmetlerinin amacı, toplum için olumsuz durumları azaltmak, hastalığı önlemek ve "sağlıklı" tanımına uygun toplum oluşturmaktır. Sağlığın ekonomi açısından iki temel önemi bulunmaktadır. Bunlardan ilki sağlıklı bir toplumun ekonomiye sağladığı katkılardır. İkincisi de sağlık durumundaki bozulmalar sonucu ortaya çıkan hastalığın, bireye ve topluma ekonomik zararlarıdır [3]. Sağlık hizmetlerinin kullanımı, temel insan haklarından biri 


\section{Derleme}

DOI: $10.34186 /$ klujes. 786837
Koç/Kırklareli University Journal of Engineering and Science 6-2(2020) 238-253

Geliş Tarihi:28.08.2020

olarak kabul edildiği için devlet müdahalesi kaçınılmazdır. Sağlık sigortasını ödeme gücüne sahip olmayan bireylerin, devlet desteği ile hizmetlerden faydalanması sağlanır. Çünkü hasta bireyin tedavi edilmemesi yalnızca, o kişiyi değil toplumu da etkileyerek, çevresindekiler için de sosyal maliyet oluşturmaktadır.

Sağlık hizmetleri tedavi, bakım, önleme ve rehabilitasyon olmak üzere 4 aktiviteyi kapsamaktadır [4]. Tedavi (care) genellikle hastanede ve kısa sürede yapılırken; bakım, önleme ve rehabilitasyon aktiviteleri için daha uzun sürelere ihtiyaç duyulmaktadır.

Sağlık hizmetleri toplumdaki hasta insanların iyileşmesi ve bakımı için ayrılan kaynak ve aktiviteler olarak da tanımlanmaktadır. Sağlık hizmetlerinin diğer tanımı da hizmetin birincil amacına göre yapılmaktadır [4].Önleme, rehabilitasyon ve bakımın (cure) ilk amacı sağlı̆̆1 geliştirmek ve sağlık çıktısını üretmektir. Tedavinin (care) ilk amacı ise, hastalığı ortadan kaldırmaya yöneliktir. Bunun yanı sıra, hasta ve bakımını yapan arasındaki ilişkinin sadece sağlık çıktısına göre değerlendirilmesi eksik bir yaklaşımdır. Bunun yerine, saygı, empati ve sempati gibi süreç ilişkili bir şekilde tanımlanmasının daha doğru bir yaklaşım olduğu söylenebilir. Fakat bakım süreçlerinin objektif değerlendirilmesi oldukça güçtür, bunun yerine ekonomik değerlendirmeler sağlık çıktısı ile ilgilenmektedir.

Sağlığı geliştirmek, ölüm oranı (mortalite) ve hastalık oranı (morbidite) gibi sağlık çıktılarını iyileştirmek ve aynı zamanda sağlıktaki eşitsizliği gidermek için "ne yapılmalı" sorusuna yanıt aranır. Bununla birlikte, sağlık kaynaklarının etkin ve eşit olarak yeniden dağıtımı için çalışılmaktadır. Bu amaçlara ulaşabilmek için iktisadın yöntemleri ve araçları (toolkit) kullanılmaktadır [4]. Sağlık sistemi kompleks yapıda olduğu için geleneksel yöntemler yerine simülasyonlarla modellenmesi ve analiz edilmesi gerçeğe daha yakın ele alınmasını sağlayacaktır. $\mathrm{Bu}$ bağlamda, bu çalışmada kompleks sistemleri modellemede en çok kullanılan kompütasyonel yöntemlerden ajan bazlı modelleme ve sistem dinamiği modellemesi ile yapılan çalışmalara yer verilecektir.

\section{Kompütasyonel Modelleme}

Son yıllarda kompütasyonel modelleme yöntemleri özellikle sağlık hizmetleri gibi kompleks yapıları araştırma ve analiz etmede önemli bir araç hâline gelmiştir. Sistem dinamiği modelleri ve 


\section{Derleme}

DOI: $10.34186 /$ klujes. 786837
Koç/Kırklareli University Journal of Engineering and Science 6-2(2020) 238-253

Geliş Tarihi:28.08.2020

ajan bazlı modelleme yöntemleri makro ve mikro seviyede sağlık sistemi davranışlarının simülasyonunu yapabilmek için en sık kullanılan yöntemler olmuştur. Söz konusu yöntemler, mikro ve makro seviye davranışları modelleyebilen, kompleks sistemlerdeki mekanizmayı açıklayabilen analiz araçlarıdır. Sağlık hizmetleri piyasasını açıklayan bu araçlar son yıllarda sıklıkla kullanılmaya başlanmıştır [5].

Diferansiyel denklemler veya ayrık olay simülasyonu (AOS) gibi araçların yetersiz kaldığı dinamik hasta akışı veya dinamik personel aktiviteleri gibi sistemler ajan bazlı modelleme ile analiz edilebilir. Ayrık olay simülasyonu yönteminde, ajan bazlı modellemeyle de yapılabilen, sıralama teorisi kullanılabilir ancak buradaki ajanlar ABM (Ajan Bazlı Modelleme)'deki gibi karar veremezler ve pasiftirler [6]. ABM gerçek hayattaki sistemlere daha yakın modelleme imkânı sağlarken, ajan olarak hastalar diğer hastalardan, sağlık çalışanlarından ya da sağlık sisteminde kendi tecrübeleri ile olaylardan öğrenebilir ve çıkarım yapabilirler [7]. Buna karşılık SDM (Sistem Dinamiği)'deki ise geri bildirimleri, sağlık hizmeti süresince yaşanan aktiviteleri ve sistemin zaman içindeki değişimini iyi bir şekilde yakalayabilmektedir. Ayrık olay simülasyonunda zamanın belli bir anının görüntüsü elde edilirken, SDM'de ise sistemin bütününün akışını, eğilimlerini ve alt sistemlerin davranışı açıklanabilmektedir [8].

Söz konusu yöntemlerden en sık kullanılanları sistem dinamiği modelleri ve ajan bazlı modelleme olup bir sonraki bölümde kısaca açıklanmaktadır.

\subsection{Sistem Dinamiği Modellemesi}

Kompütasyonel yöntemlerden sistem dinamiği modellemesi, sistem davranışlarını makro seviyede kaynakların hareketleri veya zaman içinde niceliksel değişimleri açısından inceler. SDM sistemin durum değişkenlerinin ve bunların zaman içinde değişimini diferansiyel denklemleri kullanarak sistemdeki birimlerin simülasyonunu yapar. SDM yönteminin biçimsel bir temsili olan stok akım diyagramı, stokları, oranları ve etkileyen faktörleri kullanarak sistem değişkenleri arasındaki ilişkiyi tanımlar. Akış diyagramı suyun küvete dolması ve boşalması gibi düşünülebilir; oranlar, küvete ne kadar suyun geleceğini ya da gideceğini belirlerken, söz konusu oranlar da kısıtlar ve koşullara bağlı olarak zamanla değişmektedir. SDM'de stok akım diyagramı oluşturmadan önce sistemin mantıksal bir modeli olarak genel bir döngü diyagramı oluşturulur [8]. 


\section{Derleme}

DOI: $10.34186 /$ klujes. 786837
Koç/Kırklareli University Journal of Engineering and Science 6-2(2020) 238-253

Geliş Tarihi:28.08.2020

Kabul Tarihi:31.12.2020

\subsection{Ajan Bazlı Modelleme}

SDM'nin aksine ajan bazlı modellemede sistem bütün olarak değil birim bazında ve her yönüyle temsil edilebilir. Bunun yanı sıra sadece birimlerin değil, bütün sistem davranışı aşağıdan yukarıya (buttom-up) modellenebilir. Her ajan kendi özellikleriyle ve davranış eğilimleriyle ele alınabilir. Ayrıca ajanlar, deneyimlerinden öğrenebilir, belirlenen kurallara göre kendi kararlarını verebilir, özelliklerine ve modelde oluşturulan çevreye (environment) göre, diğer ajanlarla etkileşim kurabilir. Ajanlar arası iletişim; bire bir, bire karşı çok ajanlı ve bire karşı alan (location) olacak şekilde kurulabilmektedir [9]. Bire bir iletişim, iki kişi arasındaki iletişimdir; bire karşı çok ajanlı iletişim doktorun hastayı ve yakınlarını bilgilendirmesi gibi bir iletişimdir. Son olarak merkezi anons siteminden hemşire vb. gibi sağlı personelinin bekleme salonundaki hastaları bilgilendirmesi de bire karşı alan iletişimi olarak tanımlanabilmektedir.

\section{4. İlgili Literatür}

SDM ve ABM yöntemleri sağlık sisteminde karar verme süreçlerinden acil servis optimizasyonuna kadar sağlığın geliştirilmesi ve korunması için pek çok farklı şekilde kullanılmaktadır [10]. Sağlık sisteminde maliyetli politika ve uygulamaları hayata geçirmeden önce simülasyonlarla risksiz ve düşük bütçeli olarak denemeler yapılabilir ve etkileri görülebilir. Genellikle "what if/ya olursa/farz edelim ki” senaryoları ile uygulamalar optimize edilmeye çalışılır [10].

Ayrık olay simülasyonu ve Markov modellerinin de sağlık sistemini modelleme ve sağlık ile ilgili ekonomik değerlendirmelerde geniş kullanım alanları bulunmakla birlikte bu çalışmada özellikle kompleks dinamik sistemleri modellemede tercih edilen, sistem dinamiği ve ajan bazlı modelleme yöntemlerini ele alan literatür incelenmiştir.

\subsection{Sistem Dinamiği Modellemesi ile İlgili Literatür}

Sağlık sistemi içinde acil servisler belirsizliğin en yüksek olduğu alanlardan birisidir. Sağlık hizmet talebinin ne zaman ve nasıl ortaya çıkacağı belli olmadığı için sağlık hizmet arzının her zaman yeterli olması gerekir, ancak bu talebi dengelemek için hastanenin tüm kaynakları acil servis için 
kullanılamaz. Bu noktada sağlık idarecilerinin kaynakları optimum kullanacak şekilde hastanenin bulunduğu bölgeye ve genel talep eğilimine göre planlaması ve düzenlemesi beklenmektedir. Lane [11] çalışmasında Londra'daki bir acil servis modellenerek, elektif/isteğe bağlı cerrahi müdahale kayıtlarında etkili unsurlar ve acil serviste gecikmelere neden olan faktörler belirlenmeye çalışılmıştır. Sonuç olarak yatak sayısı düşürüldüğünde acil servis kayıtlarında ve tedavi için bekleme sürelerinde artış olmuştur, bununla birlikte elektif cerrahi müdahale kayıtlarında da iptaller artmıştır. Sağlık hizmeti talebindeki artış, hasta bekleme sürelerini arttırırken sağlık çalışanlarının da uzun süre tam kapasitede çalışmasına neden olmuştur. Aynı yazarın [12] çalışmasında da yine Londra'daki bir acil servis iThink programı ile modellenmiştir. Akut hastanelerdeki hasta bekleme süresinin yatak sayısına ne kadar hassas olduğunu belirleyebilmek için çeşitli senaryolar geliştirilmiştir. İlk senaryoda yatak kapasitesi değiştirilmiş, ikinci senaryoda da kalıcı talep değişikliği yapılmıştır. Yatak kapasitesinin azaltılmasının sadece hasta bekleme sürelerini uzatmadığı ayrıca, diğer performans ölçütlerini de kötüleştirdiği sonucuna ulaşılmıştır. Kalıcı olarak sağlık hizmetleri talebi arttığında sistemin neredeyse çöktüğü, personelin tamamının kullanıldığ1 ve elektif ameliyat iptallerinin arttı̆̆ gözlenmiştir.

Haslett ve Walker'ın [13] çalışmasında Avusturalya'nın Victorya şehrindeki hastanede tek bir hizmete yönelik imkânların arttırılması, sistem dinamiği yöntemi ve iThink programı ile modellenmiştir. Büyük hastanelerden, hizmet alanı genişletilmiş akut hastanelere hasta akışında bu alanla ilgili kayıt personelinin kullandığı yerel kuralların etkisi ele alınmıştır. Yerel kurallar uygulandığında hizmet maliyeti bütçeyi \%6 aşmıştır. Aksine yerel kurallar uygulanmadığında hizmet maliyeti bütçenin \%3 altında kalmıştır. Önceliğin uygulanmadığı bekleme listesinde, tedavi için hasta bekleme süreleri kısa etkin bir döngüde kalmıştır. Büyük hastaneden küçük akut hastanelere hasta sevkinde yüksek öncelik kuralı uygulanmıştır.

Worni vd.'nin [14] çalışmasında toplam diz ameliyatı için yapılacak geri ödemeler, varis tedavisi ile aynı oranda ise, ödemelerin yapılmaması ile ilgili politika uygulanmış ve sonuçları tahmin edilmeye çalışılmıştır. Modelde, Amerika'da kemik iltihabı semptomları olan, 65 yaş üstü ve "Medicare" sigortası kapsamındaki 9,7 milyon hastanın simülasyonu Vensim programı ile yapılmıştır. Model çıktıları yeni politika uygulamasının varis tedavisi oranında 3 katı kadar düşüş olduğunu göstermiş ve ayrıca diz ameliyatı olmaya uygun hasta sayısı 6 kat azalmıştır. 


\section{Derleme}

DOI: $10.34186 /$ klujes. 786837
Koç/Kırklareli University Journal of Engineering and Science 6-2(2020) 238-253

Geliş Tarihi:28.08.2020

Mielczarek ve Zabawa'nın [15] çalışmasında kalp hastalıkları açısından gelecekte ihtiyaç duyulacak sağlık hizmetleri talebi tahmin edilmeye çalışılmıştır. Çalışmada 2002-2014 yılları arası, Polonya'daki Wroclaw bölgesinde yaşayan 60 yaş üstü yaşlı nüfus ile temel senaryo oluşturulmuştur. Çalışma sonuçlarına göre, 2015 yılından 2035 yılına kadar kalp hastası sayısı olarak; erkeklerde \%34,4 ve kadınlarda \%30,15 oranında artış olacağı tahmin edilmiştir.

Esensoy ve Carter'in [16] çalışmasında inme yaşamış hastaların tedavileri için en iyi uygulamalar araştırılmıştır. Ontorio sağlık sistemindeki 6 sektör ve bunlar arasındaki hasta akışı Vensim programı ile modellenmiştir. Çalışma sonuçlarına göre tedavi için en iyi uygulama yapıldığında tüm sektörlerde hastaların kalma süresi kısalmıştır.

Sağlık sistemini bütün olarak değerlendiren çalışmalardan biri de Semwanga'nın [17] çalışmasıdır. Uganda sağlık sisteminin dinamiklerini yakalamak amacıyla, "yenidoğan" hizmetlerinde müdahalelerin ne kadar etkisi olduğu araştırılmıştır. Sistem dinamiği modellemesi Stella programı ile yapılmıştır. Sağlık hizmetlerini bir açıdan değerlendirmek yerine, farklı hizmetler ve "yenidoğan" bebek bakımları birlikte ele alınmıştır. Toplumun sağlık konusunda eğitimi, “yenidoğanlar" için gerekli malzeme ve teçhizatın ücretsiz dağıtımı ve ayrıca motosiklet kuponlarının entegre edilmesi ile "yenidoğan” bebek ölümleri büyük ölçüde engellenmiştir. Bunların yanı sıra sosyoekonomik statüyü hedef alan müdahalelerin ise hizmet dağıtımını hedefleyen müdahalelerden çok daha fazla oranda "yenidoğan" ölümlerini azalttığı sonucuna ulaşılmıştır.

Hlavka [18] çalışmasında 6 Avrupa ülkesinde alzaymır (Alzheimer) tedavisi konusunda sağlık sistemi alt yapısının hazırlıklı olup olmadığı değerlendirilmiştir. Alzaymır tedavisinde genel kabul görmüş tek bir yöntem bulunmamakla birlikte, geliştirilme aşamasında pek çok yöntem vardır. Erken evre araştırmalarına göre, var olan tedaviler tam olarak bunamayı engellemediği için, alzaymır tedavisinin yerine hastalığın önlenmesi daha önemli hale gelmiştir. $\mathrm{Bu}$ nedenle günümüzdeki muayeneler, hastalığı önceden teşhis etmeye çalışmaktadır. Bir tedavi geliştirildiğinde, hastalarda ilk önce erken dönem hafıza kaybı ya da orta düzey bilinç düzeyi kaybı gözlenirken, alzaymır olup olmadığı test edilir ve hafıza kaybı süreci geciktirilmeye ya da yavaşlatılmaya çalışılır. Geliştirilen tedavi alzaymır hastalığının geç evrelerini hedefliyorsa, tam bu noktada sağlık sistemi açısından önemli bir zorluk ortaya çıkmaktadır. Çünkü, 28 Avrupa ülkesinde 55 yaş üstü yaklaşık 20 milyon bireyin orta düzey hafıza kaybı yaşadığı ancak bunların 
test edilmediği düşünülmektedir. Dolayısıyla alzaymır için bir tedavi geliştirildiğinde, bu tedavinin denenmesi ve süreçlerin gözlenmesi için tanısı konulmuş yeterli hasta sayısı olmadığı söylenebilir. Bu bağlamda, söz konusu çalışmada, Fransa, İspanya, Almanya, İtalya, İsveç ve İngiltere'nin alzaymır tedavisi bulunması durumunda, ilgili uygulamalar açısından hazırlıklı olup olmadıkları araştırılmıştır. Tedavileri değerlendirmek ve beklenen sayıda hasta tedavi edebilmek için SDM ile simülasyonlar yapılmıştır. Simülasyona göre, tedavi için bekleme süreleri 5 aydan (Almanya'da) 19 aya (Fransa'da) kadar değişmiştir. Bekleme süresi olmaksızın tedaviye ulaşma ise, Almanya'da 2030, Fransa'da 2033, İngiltere'de 2042 ve İspanya'da 2044 y1lında gerçekleşebilmiştir. Çoğu ülkenin, tedavinin dağıtımı açısından zorluk yaşayacağı öngörülmüştür. Eğer hastalığın tedavisi 2020 yılında uygulanabilir hâle gelirse, öngörülen kapasite ve tedavi dağıtımı kısıtları altında, 2020-2044 yılları arasında hafif düzey biliş bozukluğu olan 1 milyondan fazla hastanın, orta düzey alzaymır hastalığını yaşayacağı tahmin edilmiştir.

Zhu vd.'lerinin [19] çalışmasında, İngiltere' de antibiyotik reçetesi yazılma oranının optimizasyonu konusunda yapılabilecek müdahaleler sistem dinamiği modellemesi ile ele alınmıştır. Antibiyotik direncinin oluşmaması amacıyla antibiyotik tüketimini azaltmaya yönelik pek çok davranışsal müdahale yapılmasına rağmen, doktorların antibiyotik yazma oranı üzerinde sınırlı etkisi olmuştur. Bu bağlamda, bu çalışmada bir hastanede antibiyotik yazılma sürecinin, karar verme aşamaları iThink programı kullanılarak sistem dinamiği yaklaşımı ile modellenmiştir. Hastane verileri kullanılarak "ya olursa” senaryoları geliştirilmiştir. Yapısal doğrulama ve parametre doğrulama testi, ekstrem durum testi, tutarlılık ve davranışsal duyarlılık testleri yapılmıştır. Modelde stok akım metodolojisi ile doktorların reçete yazma süreci oluşturulmuştur. Stok seviyesi, farklı aşamalarda reçete yazılma kararı verilen hasta sayısı olmak üzere, akım ise, birim zamanda reçetesi yazılma süreci devam eden hasta sayısını temsil etmiştir. Mikrobiyoloji laboratuvarı da alt sistem olarak modele alınmıştır. Ayrıca reçete yazımı kurallarına uymayan tecrübeli ve tecrübesiz personel yüzdesi ile mikrobiyologların gözlemlerini dikkate alarak reçete yazma kuralına uyan personel yüzdesi ana parametreler olarak kullanılmıştır. Çalışma sonuçları hastane yöneticilerine hangi uygulamaların yapılması gerektiği konusunda kantitatif bir kanıt sunmuştur. Buna göre, mikrobiyoloji laboratuvarında hızlı tanı araçlarının kullanılması ya da tanı testlerinin daha kısa sürede yapılması antibiyotik reçetesi yazılma oranını azaltmıştır. 
Derleme

DOI: $10.34186 /$ klujes. 786837
Koç/Kırklareli University Journal of Engineering and Science 6-2(2020) 238-253

Geliş Tarihi:28.08.2020

\subsection{Ajan Bazlı Modelleme ile İlgili Literatür}

Huynh vd.'lerinin [20] çalışmasında ilaç kayıt güvenliğinin sağlanması konusunda ajan bazlı modelleme kullanılmıştır. Bu bağlamda, ilaç kayıt sürecinde (IKS) ilgili hemşirenin iş akışı ele alınmış ve yeniden dizayn edilmiştir. Çalışmada hemşirelerin hastalara ait ilaçların kaydını yaptığı yerel ilaç merkezi NetLogo programı kullanılarak modellenmiştir. İKS görev süreci sıralaması yeni bir protokol ile değiştirilmiş ve böylece görev için ayrılan süreler kısalmıştır. Simülasyonda, hemşireler pilot çalışmadaki gibi en yüksek sıklıkla gözlenmiş sıralamayı uyguladığında ilaç kayıt görev sürelerini daha etkin kullanabilmişlerdir.

Einzinger vd.'lerinin [21] çalışmasında sağlık hizmeti sağlayıcılar ve geri ödemeler ele alınmıştır. Ajan bazlı GAR-DRG modeli ile Avusturalya'daki ayaktan tedavi hizmetlerinde geri ödeme planları karşılaştırılmıştır. Simülasyonda hastalar medikal sorunlar yaşar ve tıbbi hizmete ihtiyaç duyar. Bu noktada sağlık hizmeti sağlayıcılarına başvurur. Geri ödeme sistemi, hastaların sağlık kurumlarını ziyaretleri sırasında kapsamlı bilgi toplar. Model tutulan hasta verilerinin optimal kullanımı için dizayn edilmiştir. Ana ajanlar hastalar, sağlık hizmeti sağlayıcılar, geri ödeme sistemi ve sağlık hizmetleri piyasası olup, AnyLogic programı ile modellenmiştir. Sonuçta Avusturalya için geri ödeme planlarını karşılaştırabilecek bir araç oluşturulmuştur.

Viana vd.'lerinin [22] çalışmasında gebe ayaktan tedavi kliniğinde, sağlık hizmeti talebi belirsiz olan doğumu gecikmiş hastalar aracılığıyla hasta akışını açıklamak ve geliştirmek için ajan bazlı modelleme kullanılmıştır. Norveç’te Akershus Üniversitesi Hastanesi’ndeki doğumu gecikmiş gebe ayaktan tedavi kliniği, gebe kliniği ve doğum sonrası kliniği NetLogo programı ile modellenmiştir. Simülasyon sonucunda beklendiği gibi klinikteki ebe sayısının artması ile kaynakların kullanımı azalmıştır. Buna karşılık, büyük oranda talep artışı olursa, ebe sayısı artsa bile, bu talebi karşılayabilmek için daha fazla doktor görev yapmak zorunda kalmıştır.

Chang ve Tassier'in [23] çalışmasında, bölgesel aşılama kapsamında ve epidemik bir hastalığın ajan bazlı modellemesi yapılmıştır. Çalışmada örnek olarak mevsimsel grip salgını yaşandığında, yüksek ve düşük aşılama yapılan bölgelerdeki epideminin ve dışsallıkların şiddeti araştırılmıştır. Epidemi boyutları aşı kapsamının ne kadar heterojen olduğuna, toplumdaki etkileşim yapısına ve toplumun, sürü bağışıklığına (herd immunity) ne kadar yakın olduğuna göre değişmiştir. Toplam aşı seviyesi sabit tutulduğunda, ortalama epidemi boyutu artmıştır. Bölgesel aşılama oranları 
değişkenliği yüksek iken, sürü bağışıklığı için daha büyük ölçüde aşılamaların yapılması gerektiği gözlenmiştir. Toplumda etkileşim yüksek ise, hastalık daha kolay yayılacağı için söz konusu aşılama gerekliliği de daha yüksek olmuştur. Buna karşılık, bölgeler arası bağlantılar ve aşılama seviyesi yeterli olduğunda, ortalama epidemi boyutu da azalmıştır. Ayrıca çalışmada, farklı aşılama kapsamı bulunan bölgelerde, dışsallık şiddetinin, toplumun sürü bağışıklığı yakınlığına göre, değiştiği sonucuna ulaşılmıştır.

Sok ve Fischer'ın [24] çalışmasında, hayvan aşılarının beklenen ters etkileri, devlet ve çiftçi arası iletişim stratejileri ve devlet desteklerine göre farklılık gösteren aşılama planlarını dizayn etmek için ajan bazlı modelleme yapılmıştır. Modelde NetLogo programı kullanılarak, çeşitli senaryoların simülasyonu yapılmıştır. Çiftlik hayvanlarında epidemik hastalık olması durumunda, devlet desteği ve çiftçilerle iletişimin minimal seviyede kurulduğu ve belirli bir plan olması senaryoları ele alınmıştır. Sonuç olarak hastalık görüldüğünde, çiftçinin ne yapması gerektiğine dair plan olması durumunda, aşılama oranlarının arttığı gözlenmiştir. Çalışma sonuçları, iyi planlanmış risk yönetim stratejilerinin, devletin finansal desteği kadar önemli olduğunu göstermiştir. Ayrıca söz konusu planlar ile hastalıklara karşı hayvanların aşılanma oranı artmıştır.

\subsection{Hibrit Modeller ile ilgili Literatür}

İki ya da daha fazla yöntem kullanılarak oluşturulan modeller hibrit modellerdir. Ayrı ayrı modelleme yöntemlerinin kısıtları bulunmaktadır. Hibrit modeller ile bu kısıtlar ortadan kaldırılarak, gerçeğe daha yakın modelleme yapılabilmektedir [25]. Bazı modeller bireysel hasta ve sağlık personel çeşitliliğini, bazıları da sağlık sisteminin kompleks yapısını daha iyi yansıtabilir. $\mathrm{Bu}$ çalışma kapsamında ajan bazlı modelleme, ayrık olay simülasyonu ve sistem dinamiği modellemelerini ikili olarak birlikte kullanan çalışmalar incelenecektir.

Sistem dinamiği ve ayrık olay simülasyonu yöntemlerini birlikte kullanan Brailsford vd.'lerinin [26] çalışmasında yerel yönetimlerin yaşlı nüfusun sağlık hizmetleri servisleri ve desteklerine ulaşımını nasıl kolaylaştırabileceği ele alınmıştır. Bu konuda yeni bir iletişim merkezi uygulamasının uzun dönemli etkisi değerlendirilmiştir. İngiltere’deki Hampshire Belediyesi çağrı merkezi modele alınmıştır. Söz konusu merkez yaşlılara tavsiye vermiş ya da uygun sağlık hizmetine yönlendirmiştir. SDM için Vensim ve AOS için de Simul8 programları kullanılmıştır. 
Simülasyonda sağlı durumu kötü olup ikinci aramayı yapan hastalar (ilk aramada iletişim kurmada sorun yaşayanlar) çağrı merkezindeki yetkili kişilerden tavsiye alarak iyileşebilmişlerdir. Böylece sağlık durumu kötü olan yaşlı sayısı önemli miktarda azalmıştır.

Djanatliev vd.'lerinin [27] çalışmasında ileriye yönelik sağlık teknolojileri değerlendirmesi (ProHTA- Prospective Health Technology Assessment) için ajan bazlı modelleme ve sistem dinamiği yaklaşımları birlikte kullanılmıştır. Sağlık teknolojilerinin değerlendirilmesinde HTA, EarlyHTA and Horizon Scanning gibi farklı araçlar kullanılmaktadır. Bunlar var olan teknolojileri değerlendirmeye imkân verirken; ProHTA aracında ise sağlık hizmetleri ile ilgili bir ürün geliştirilmeden veya dizayn edilmeden önce değerlendirilebilmektedir. Modellemede AnyLogic programı kullanılmıştır. Ana simülasyonlar ve hasta davranışlarının detaylı iş akışları ABM ile oluşturulurken, bunun dişındaki çevre sistem dinamiği ile modellenmiştir. Tüm simülasyonlar farklı modüllere bölünerek komplekslik en iyi şekilde modellenebilmiş ve modül parçaları farklı senaryolarda kullanılabilmiştir. Kullanım senaryosu (use case) örnek ile ele alınmıştır. Mobil İnme Birimleri (MİB-Mobile Stroke Units) yeni bir sağlık hizmet aracı olarak ele alınmış ve uygulama sonrasında trombosit oranındaki yükseliş değerlendirilmiştir. Bu değerlendirme sonuçları alandaki uzman doktor ve diğer sağlık çalışanlarının da onayını alabilmiştir. Model ile sağlık hizmetleri için geliştirilen teknolojik bir ürün, nihai üretimi yapılmadan önce sanal ortamda değerlendirilebilmiştir.

Kittipittayakorn ve Ying'in [28] çalışmasında hasta bekleme sürelerini azaltmak için uygulanabilecek politikalar, ajan bazlı modelleme ve kesikli olay simülasyonu ile değerlendirilmiştir. Çalışmada hastanelere randevulu ve randevusuz hasta kabul edildiğinde, hasta bekleme sürelerinin arttığı belirtilmiştir. Bekleme sürelerini azaltmak için departmanlara danışma birimleri eklenmiştir. Çalışmada sadece hastanenin ortopedi departmanı için danışma birimleri eklendiğinde, bu birimdeki hasta bekleme sürelerinin yaklaşık $30 \mathrm{dk}$ azaldığı gözlenmiştir. Hastanenin ortopedi departmanındaki alanları modellemede ayrık olay simülasyonu kullanılırken, hasta ve sağlık çalışanları da ajan bazlı modelleme ile simülasyona alınmıştır. 
Derleme

DOI: $10.34186 /$ klujes. 786837
Koç/Kırklareli University Journal of Engineering and Science 6-2(2020) 238-253

Geliş Tarihi:28.08.2020

Kabul Tarihi:31.12.2020

Tablo 1: Sağlık Hizmetleri Piyasasında Kullanılan SDM ve ABM Yöntemlerinin Özeti

\begin{tabular}{|c|c|c|}
\hline & $\mathrm{ABM}$ & SDM \\
\hline \multirow{5}{*}{ Çalışmanın Amacı } & $\begin{array}{l}\text { İstenmeyen sağlık } \\
\text { çıktılarının azaltılması } \\
{[27]}\end{array}$ & $\begin{array}{l}\text { İstenmeyen sağlık çıktılarının } \\
\text { azaltılması } \\
\text { [17] [27] [14] }\end{array}$ \\
\hline & $\begin{array}{l}\text { Herhangi bir tıbbî müdahale } \\
\text { almadan hastaneyi terk eden } \\
\text { hasta sayısının azaltılmaya } \\
\text { çalışılması [21] }\end{array}$ & $\begin{array}{l}\text { Alınan sağlık hizmetleri kalitesini } \\
\text { arttırmak } \\
\text { [17] }\end{array}$ \\
\hline & $\begin{array}{l}\text { Sağlık personelinin görevini } \\
\text { yerine getirirken harcadığı } \\
\text { performansın azaltılması, } \\
\text { hastaların hizmet almak için } \\
\text { bekleme ve sistemde kalma } \\
\text { süresinin kısaltılması } \\
{[20][28]}\end{array}$ & $\begin{array}{l}\text { Sağlık hizmetleri kapasitesinin } \\
\text { yeterli hâle getirilmesi ve hastaların } \\
\text { hastanede kalış sürelerinin } \\
\text { azaltılması } \\
\text { [26] [16] }\end{array}$ \\
\hline & $\begin{array}{l}\text { Sağlık sigortası geri ödeme } \\
\text { planlarının } \\
\text { karşılaştırılabilmesi için } \\
\text { araç geliştirilmesi } \\
\text { [21] }\end{array}$ & $\begin{array}{l}\text { Sağlık hizmetlerinin toplam } \\
\text { maliyetini azaltmak } \\
{[27][14]}\end{array}$ \\
\hline & $\begin{array}{l}\text { Aşı planlamaları ve bu konu } \\
\text { ile ilgili uygulanacak } \\
\text { politikaların, salgın hastalık } \\
\text { durumunda etkinliğinin } \\
\text { değerlendirilmesi [24] [23] }\end{array}$ & $\begin{array}{l}\text { Acil serviste istenmeyen durumlara } \\
\text { neden olan faktörlerin belirlenmesi } \\
{[11][12]}\end{array}$ \\
\hline
\end{tabular}


Derleme

DOI: $10.34186 /$ klujes. 786837

\begin{tabular}{|c|c|c|}
\hline \multirow{5}{*}{ Validasyon Yöntemleri } & $\begin{array}{l}\text { Model çıktıları uzmanlar } \\
\text { tarafından değerlendirilmiş } \\
\text { ve doğrulanmıştır. } \\
\text { [22] }\end{array}$ & $\begin{array}{l}\text { Model çıtıları uzmanlar tarafından } \\
\text { değerlendirilmiş ve doğrulanmıştır } \\
{[12][17] \text {. }}\end{array}$ \\
\hline & $\begin{array}{l}\text { Duyarlılık (Sensitivity) } \\
\text { analizi yapılmıştır. } \\
{[21]}\end{array}$ & $\begin{array}{lll}\text { Yapısal } & \text { geçerlilik } & \text { testleri } \\
\text { yapılmıştır. } & & \\
{[16][17]} & & \end{array}$ \\
\hline & $\begin{array}{l}\text { Ekstrem durum testleri } \\
\text { yapılmıştır. [22] }\end{array}$ & $\begin{array}{l}\text { Yapısal geçerlilik için uzmanların } \\
\text { onayı alınmıştır. [11] }\end{array}$ \\
\hline & $\begin{array}{l}\text { Model çıktıları tarihsel } \\
\text { veriler ve daha önce yapılan } \\
\text { çalışmalarla } \\
\text { karşılaştırılmıştır. [22] [20] } \\
\text { [21] }\end{array}$ & $\begin{array}{l}\text { Duyarlılık analizinde model } \\
\text { çıktılarının ana parametrelerdeki } \\
\text { değişimlere ne kadar duyarlı olduğu } \\
\text { test edilmiştir. [17] [12] }\end{array}$ \\
\hline & $\begin{array}{l}\text { F-testi (Huynh) ve T-testi } \\
\text { kullanılmıştır. } \\
\text { [20] [28] }\end{array}$ & $\begin{array}{l}\text { Uygulanan politikaların hataya } \\
\text { karşı dayanıklılığı (robustness) ve } \\
\text { etkililiği test edilmiştir. [16] [14] }\end{array}$ \\
\hline \multirow{3}{*}{ Kullanılan programlar } & $\begin{array}{l}\text { AnyLogic } \\
{[21]}\end{array}$ & $\begin{array}{l}\text { iThink } \\
\text { [13] [12] [19] }\end{array}$ \\
\hline & NetLogo [20] [24] & Simul8 [26] \\
\hline & & Vensim [14] [16] [26] \\
\hline
\end{tabular}

\section{SONUÇ}

Yapılan derleme sonucunda sistem dinamiği modellemesi, ajan bazlı modelleme ve ayrık olay simülasyonu yöntemleri sağlık hizmetlerinde çeşitli alanlarda hizmetlerin performansını değerlendirmek, hizmetleri yeniden düzenlemek ve geliştirmek için kullanılmıştır. Söz konusu 


\section{Derleme}

DOI: $10.34186 /$ klujes. 786837
Koç/Kırklareli University Journal of Engineering and Science 6-2(2020) 238-253

Geliş Tarihi:28.08.2020

yöntemlerin, sağlık hizmetleri piyasasında; yaşlı bakımı veya uzun dönem bakım hizmetlerinin değerlendirilmesinde, acil servisin performansı konusunda, sağlık sigortası, sağlık hizmet sağlayıcıları ve geri ödeme sistemlerinin planlanmasında ve düzenlenmesinde, salgın hastalıkların yayılma şekilleri ve bulaşma riskini azaltmak için alınabilecek önlem senaryolarının simülasyonunda ve son olarak yenidoğan, doğum sonrası ve çocuk sağlı̆̆ konularında hizmetleri değerlendirmek ve geliştirmek amacıyla kullanıldığı gözlenmiş̧ir.

Çalışmada SDM, ABM ve hibrit modelleme yöntemlerinin, sağlık hizmetleri sisteminin simülasyonunu yapma, değerlendirme ve uygulanacak politikaları hayata geçirmeden önce sanal ortamda gözleme konusunda sıklıkla kullanıldığı görülmüş̧ür. ABM yöntemi sistemi birim bazında değerlendirme konusunda daha üstün iken, SDM yöntemi de stok akım yaklaşımı ile uygulamada kolaylık sağlayarak, sistemi genel olarak değerlendirmede tercih edilmektedir.

Sağlık hizmetleri ve sağlık hizmetleri piyasası kompleks adaptif yapı olduğu için klasik değerlendirme ve analiz etme araçları, gerçeği yansıtma konusunda yetersiz kalmaktadır. Dolayısıyla etkin çözüm konusunda klasik Newton matematiği kullanılarak bulunan ve tek çözüm veren yöntemler yerine, günümüzün ileri düzey teknolojisiyle oluşturulmuş simülasyon yöntemleriyle bulunan çözümlerin diğer bir ifadeyle tek bir çözüm yerine çözüm kümeleri sunan yöntemlerin sağlık hizmetleri ve sağlık hizmetleri piyasasını değerlendirmede daha üstün olduğu söylenebilir.

\section{KAYNAKLAR}

[1] J. H. Holland ve J. H. Miller, "American Economic Association Artificial Adaptive Agents in Economic Theory Author ( $s$ ): John H . Holland and John H . Miller Source: The American Economic Review, Vol . 81, No . 2, Papers and Proceedings of the Hundred and Third Annual Meeting of th", Am. Econ. Rev., c. 81, sayı 2, ss. 365-370, 1991.

[2] A. Kitson $v d$., "Using complexity and network concepts to inform healthcare knowledge translation”, Int. J. Heal. Policy Manag., c. 7, sayı 3, ss. 231-243, 2018.

[3] F. Ersöz, "Türkiye ile OECD ülkelerinin sağlık düzeyleri ve sağlık harcamalarının analizi”, İstatistikçiler Dergisilistatistik ve Aktüerya, c. 1, say1 2, ss. 95-104, 2008.

[4] J. A. Olsen, Principles in Health Economics and Policy. 2009.

[5] R. Cassidy $v d$., "Mathematical modelling for health systems research: A systematic review of system dynamics and agent-based models", BMC Health Serv. Res., c. 19, say1 1, ss. 15- 


\section{Derleme}

DOI: $10.34186 /$ klujes. 786837
Koç/Kırklareli University Journal of Engineering and Science 6-2(2020) 238-253

Geliş Tarihi:28.08.2020

17, 2019.

[6] M. Allen $v d$., "Right cot, right place, right time: improving the design and organisation of neonatal care networks - a computer simulation study", Heal. Serv. Deliv. Res., c. 3, say1 20, ss. 1-128, 2015.

[7] Z. Liu, E. Cabrera, D. Rexachs, ve E. Luque, "A Generalized Agent-Based Model to Simulate Emergency Departments”, Sixth Int. Conf. Adv. Syst. Simul., sayı c, ss. 65-70, 2014.

[8] P. Liu ve S. Wu, "An agent-based simulation model to study accountable care organizations", Health Care Manag. Sci., c. 19, say1 1, ss. 89-101, Mar. 2016.

[9] U. Wilensky ve W. Rand, An introduction to agent-based modeling, say1 January. 2015.

[10] M. Atkinson, R. Wells, A. Page, A. Dominello, M. Haines, ve A. Wilson, "Applications of system dynamics modelling to support health policy", Public Heal. Res. Pract., c. 25, say1 3, ss. 1-8, 2015.

[11] D. Lane ve J. Rosenhead, "Emergency - but no accident - a system dynamics study of casualty waiting times in the British NHS - CentAUR", Eurohealth (Lond)., c. 4, sayı 1, ss. 34-36, 1998.

[12] D. Lane, C. Monefeldt, ve J. Rosenhead, "Looking in the wrong place for healthcare improvements: A system dynamics study of an accident and emergency department", $J$. Oper. Res. Soc., c. 51, say1 5, ss. 518-531, 2000.

[13] T. Haslett ve B. C. Walker, "The dynamics of local rules in hospital admission processes", Aust. Heal. Rev., c. 26, say1 3, s. 98, 2003.

[14] M. Worni $v d$., "System Dynamics to Model the Unintended Consequences of Denying Payment for Venous Thromboembolism after Total Knee Arthroplasty", PLoS One, c. 7, say1 4, s. e30578, Nis. 2012.

[15] B. Mielczarek ve J. Zabawa, "MODELING HEALTHCARE DEMAND USING A HYBRID SIMULATION APPROACH", sayı August, ss. 1535-1546, 2016.

[16] A. V. Esensoy ve M. W. Carter, "High-fidelity whole-system patient flow modeling to assess health care transformation policies", Eur. J. Oper. Res., c. 266, say1 1, ss. 221-237, 2018.

[17] A. R. Semwanga, S. Nakubulwa, ve T. Adam, "Applying a system dynamics modelling approach to explore policy options for improving neonatal health in Uganda", Heal. Res. Policy Syst., c. 14, say1 1, ss. 1-17, 2016.

[18] J. Hlavka, S. Mattke, ve J. Liu, "Assessing the Preparedness of the Health Care System 


\section{Derleme}

DOI: $10.34186 /$ klujes. 786837
Koç/Kırklareli University Journal of Engineering and Science 6-2(2020) 238-253

Geliş Tarihi:28.08.2020

Infrastructure in Six European Countries for an Alzheimer's Treatment", Assess. Prep. Heal. Care Syst. Infrastruct. Six Eur. Ctries. an Alzheimer's Treat., c. 8, sayı 3, Eyl. 2018.

[19] N. J. Zhu, R. Ahmad, A. Holmes, J. V. Robotham, R. Lebcir, ve R. Atun, "System dynamics modelling to formulate policy interventions to optimise antibiotic prescribing in hospitals", J. Oper. Res. Soc., c. 0, say1 0, ss. 1-13, 2020.

[20] N. Huynh, R. Snyder, J. M. Vidal, A. S. Tavakoli, ve B. Cai, "Application of computer simulation modeling to medication administration process redesign", J. Healthc. Eng., c. 3, say1 4, ss. 649-662, 2012.

[21] P. Einzinger, N. Popper, F. Breitenecker, N. Pfeffer, R. Jung, ve G. Endel, "The GAP-DRG model: Simulation of outpatient care for comparison of different reimbursement schemes", Proc. 2013 Winter Simul. Conf. - Simul. Mak. Decis. a Complex World, WSC 2013, ss. 22992308, 2013.

[22] J. Viana, T. B. Simonsen, F. A. Dahl, ve K. Flo, "A hybrid discrete event agent based overdue pregnancy outpatient clinic simulation model", Proc. - Winter Simul. Conf., c. 2018-Decem, ss. 1488-1499, 2018.

[23] M. H. Chang ve T. Tassier, "Spatially Heterogeneous Vaccine Coverage and Externalities in a Computational Model of Epidemics", Comput. Econ., 2019.

[24] J. Sok ve E. A. J. Fischer, "Farmers' heterogeneous motives, voluntary vaccination and disease spread: An agent-based model", Eur. Rev. Agric. Econ., c. 47, say1 3, ss. 1-22, 2019.

[25] S. Brailsford, "Proceedings of the 2007 Winter Simulation Conference S. G. Henderson, B. Biller, M.-H. Hsieh, J. Shortle, J. D. Tew, and R. R. Barton, eds.”, ss. 1436-1448, 2007.

[26] S. C. Brailsford, S. M. Desai, ve J. Viana, "Summary for Policymakers", içinde Proceedings of the 2010 Winter Simulation Conference, 2010, c. 53, say1 9, ss. 1-30.

[27] A. Djanatliev, R. German, P. Kolominsky-rabas, ve B. Hofmann, "Technology can be represented in this context by medical devices , pharmaceuticals , procedures , ther-", Proc. 2012 Winter Simul. Conf., 2012.

[28] C. Kittipittayakorn ve K.-C. Ying, "Using the Integration of Discrete Event and AgentBased Simulation to Enhance Outpatient Service Quality in an Orthopedic Department", J. Healthc. Eng., c. 2016, ss. 1-8, 2016. 